\title{
IPTEKS IMPLEMENTASI PERENCANAAN PEMBANGUNAN DAERAH BERBASIS E-PLANNING PADA BADAN PERENCANAAN DAN PEMBANGUNAN DAERAH (BAPPEDA) SULAWESI UTARA
}

\author{
Harry Patrick Paat ${ }^{1}$, Edward Fredrik Tuju $^{2}$, Meily Y. B Kalalo ${ }^{3}$ \\ 1,2,3 Jurusan Akuntansi, Fakultas Ekonomi dan Bisnis Universitas Sam Ratulangi, Jl. Kampus Unsrat, \\ Manado, 95115, Indonesia \\ E-mail : paatharry765@gmail.com
}

\begin{abstract}
As per Permendagri No. 86 of 2017 concerning Procedures for Regional Development Planning, good and effective management of Regional Development can increase the rate of economic growth and community welfare. For this reason, the Government through the Regional Planning and Development Agency (BAPPEDA) of North Sulawesi Province as part of the Regional Organization (OPD) is an element of planning for regional government organizers and has the task of assisting the Governor in the preparation and implementation of regional policies regional development planning. The purpose of this study is to evaluate and analyze the results of the preparation of planning documents and inputting RPJMD, Renstra, RKPD and E-planning based Renja as mandated in Ministerial Regulation number 86 of 2017 through the preparation stages of preparation, drafting, drafting, implementing Musrenbang, final draft formulation and stipulation. The method applied is the guideline for operating the annual parameter e-planning module by the Deputy for Supervision of Regional Financial Management. The results of this study indicate that BAPPEDA of North Sulawesi Province has implemented the mandate of Permendagri No. 86 of 2017, but have not optimized the use of e-planning applications. For this reason, the future BAPPEDA of North Sulawesi Province can improve its performance through e-planning.
\end{abstract}

Keywords: Implementation, Regional Development Planning, E-planning

\section{PENDAHULUAN}

Sesuai amanat Undang-Undang Republik Indonesia nomor 23 tahun 2014 tentang Pemerintahan Daerah, dimana pemerintah Daerah dalam tugas penyelenggarannya mampu memajukan dan mensejahterakan masyarakatnya lewat pembangunan Daerah maka perencanaannya harus dilakukan secara baik serta meminimalisirkan faktor-faktor penghambat pembangunan. Organisasi Perangkat Daerah (OPD) di Provinsi Sulawesi Utara yang berikan kewenangan dalam menyusun perencanaan pembangunan Daerah Pemerintah yaitu BAPPEDA. BAPPEDA Sulut menjadi unsur perencanaan penyelenggara pemerintahan daerah yang juga mempunyai tugas membantu Kepala Daerah dalam hal ini Gubernur, serta memiliki wilayah kerja seluruh Kabupaten/Kota dan Provinsi yang ada di Sulawesi Utara. Dalam menjalankan tugas dan fungsi agar lebih efektif dan efisien dalam penyusunan dokumen perencanaan BAPPEDA telah menggunakan aplikasi e-planning yang diberikan oleh BPKP secara gratis. Penggunaan aplikasi e-planning telah sejalan dengan amanat Permendagri nomor 86 tahun 2017 pasal 14 yang menyatakan bahwa proses penyusunan RPJPD, RPJMD, dan RKPD Provinsi Sulut harus berbasis e-planning. Dengan terimplementasinya e-planning maka seluruh program kerja yang dilakukan dapat terintegrasi, dioptimalkan dan kemungkinan tidak selarasnya dokumen perencanaan pembangunan Daerah dapat diatasi. 


\section{TINJAUAN PUSTAKA}

Perencanaan Pembangunan Daerah. Menurut (Permendagri nomor 86 tahun 2017), "Perencanaan pembangunan Daerah adalah suatu proses untuk menentukan kebijakan masa depan, melalui urutan pilihan, yang melibatkan berbagai unsur pemangku kepentingan, guna pemanfaatan dan pengalokasian sumber daya yang ada dalam jangka waktu tertentu di Daerah.

Aplikasi E-planning. Sistem Informasi Perencanaan Pembangunan Daerah ( $e$ planning) adalah sebuah alat penyusunan RPJMD, Renstra, RKPD, Renja Pemerintah Daerah agar dapat terselesaikan dengan mudah, cepat, tepat dalam penyusunan dokumen perencanaan sebagaimana diamanatkan dalam Permendagri No. 86 Tahun 2017. Dengan adanya aplikasi e-planning ini, Pemerintah Sulawesi Utara $\mathrm{Cq}$ BAPPEDA dapat mengoptimalkan dan menyajikan analisa yang sangat penting bagi para stakeholder. Eplanning menjadi alat bantu BAPPEDA Sulwesi Utara dalam kegiatan perencanaan, pengendalian dan evaluasi pelaksanaan rencana pembangunan daerah serta selaku koordinator dalam penyusunan program kerja OPD sehingga perencanaan pembangunan daerah yang telah dibuat dapat berjalan secara efektif, efisien dan terintegrasi.

\section{METODE DAN TEKNIK IMPLEMENTASI E-PLANNING}

\subsection{Metode implementasi E-planning}

Metode Implementasi yang digunakan adalah pedoman pengoperasian SIMDA perencanaan (e-planning) modul parameter lima tahunan dan tahunan yang dikeluarkan oleh BPKP Cq Deputi Pengawasan Bidang Penyelenggaran Keuangan Daerah.

\subsection{Teknik implementasi E-planning}

Teknik Implementasi yang digunakan adalah mengevaluasi dan menganalisis hasil dari proses penyusunan dokumen perencanaan yaitu penginputan RPJMD, Renstra, RKPD dan Renja berbasis e-planning sebagaimana diamanatkan dalam Peraturan Menteri nomor 86 Tahun 2017 melalui tahapan persiapan penyusunan, penyusunan rancangan awal, penyusunan rancangan, pelaksanaan Musrenbang, perumusan rancangan akhir dan penetapan.

\section{PEMBAHASAN}

\subsection{Gambaran Objek Implementasi}

Badan Perencanaan dan Pembangunan Daerah Provinsi Sulawesi Utara (BAPPEDA SULUT) merupakan salah satu Organisasi Perangkat Daerah (OPD), yang beralamat di Jalan 17 Agustus No. 73 Teling Atas dengan struktur organisasi dalam kepemimpinannya dikepalai oleh Kepala Badan yang melaksanakan dan mengemban amanat dari Kepala Daerah Provinsi maupun Kab/Kota. Bappeda Provinsi Sulawesi Utara dalam melaksanakan tugas dibidang Perencanaan Pembangunan Daerah serta berperan untuk menyusun dan melaksanakan kebijakan Daerah, melalui Permendagri No. 86 tahun 2017 menyangkut tugas, fungsi, dan tujuan BAPPEDA dalam menyusunan Dokumen Perencanaan Provinsi Sulut. Keterkaitannya pada pembangunan Daerah BAPPEDA Sulawesi Utara berperan dalam meningkatan dan melakukan pemerataan pendapatan masyarakat, kesempatan kerja, lapangan kerja, peningkatan fasilitas dan layanan publik yang layak, serta daya saing daerah.

Implementasi Perencanaan Pembangunan Daerah Berbasis E-planning pada BAPPEDA Provinsi Sulawesi Utara. Dengan mengimplementasikan Perencanaan Pembangunan Daerah Berbasis e-planning (SIMDA Perencanaan) pada BAPPEDA Sulut dapat membantu efisiensi serta efektivitas kinerja BAPPEDA, yaitu:

a. Meningkatkan/mendorong implementasi sistem perencanaan (e-planning), e-musrenbang dan e-ASB serta $e$-budgeting secara penuh dalam penyusunan penganggaran pemerintah daerah. 
b. Meningkatkan kapasitas dan kapabilitas sumber daya Pemerintah Daerah dengan melakukan bimbingan teknis, workshop, dan asistensi sistem perencanaan pembangunan daerah.

\section{Alur serta ruang lingkup SIMDA Perencanaan (E-planning)}

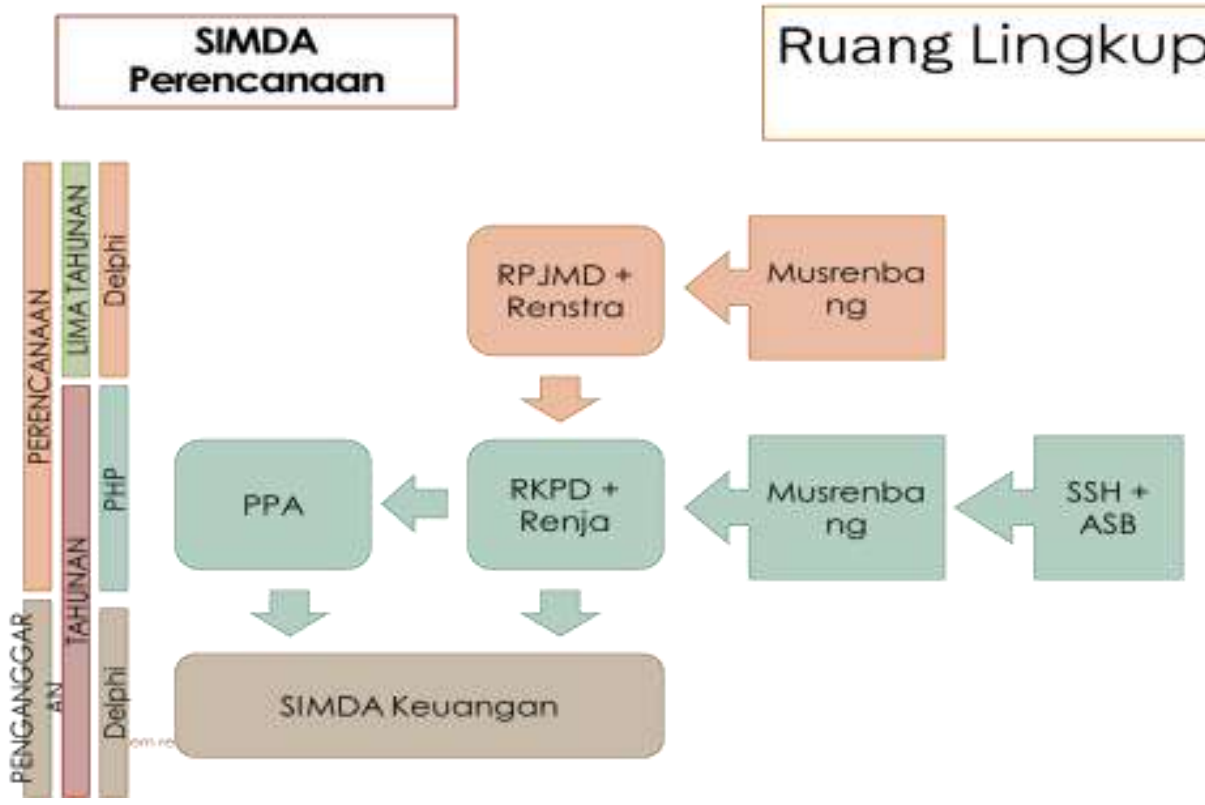

Sumber data: Materi SIMDA Perencanaan BPKP

Tahapan Implementasi. Tahapan implementasi yang dilaksanakan BAPPEDA Provinsi Sulawessi Utara, yaitu:

\begin{tabular}{|c|c|c|}
\hline No & \multicolumn{2}{|c|}{ Tahapan implementasi } \\
\hline \multirow[t]{3}{*}{1.} & Implementasi Penyusunan RPJMD & $\begin{array}{l}\text { a. Bimtek kepada seluruh fungsi perencanaan } \\
\text { (Bappeda dan SKPD). }\end{array}$ \\
\hline & & $\begin{array}{l}\text { b. Input data dalam proses perencanaan } 5 \text { Tahunan ( } \\
\text { Asistensi BPKP). }\end{array}$ \\
\hline & & $\begin{array}{l}\text { c. Output berupa dokumen perencanaan RPJMD dan } \\
\text { Renstra. }\end{array}$ \\
\hline 2. & $\begin{array}{l}\text { Implementasi Penyusunan ASB } \\
\text { dan SSH }\end{array}$ & a. $\quad$ Bentuk Tim Penyusunan ASB dan SSH. \\
\hline & & b. Bimtek kepada Tim Penyusunan ASB dan SSH. \\
\hline & & c. Rumuskan dan Susun ASB dan SSH. \\
\hline & & $\begin{array}{ll}\text { d. Input Data ASB dan SSH dalam Aplikasi } \\
\text { (asistensi). }\end{array}$ \\
\hline & & $\begin{array}{l}\text { e. Output nya berupa perkada tentang ASB dan SSH } \\
\text { untuk penyusunan RKPD dan Renja. }\end{array}$ \\
\hline \multirow[t]{5}{*}{3.} & $\begin{array}{l}\text { Implementasi Penyusunan RKPD dan } \\
\text { Renja serta PPAS }\end{array}$ & $\begin{array}{l}\text { a. Menyiapkan infrastruktur web untuk instalasi } \\
\text { aplikasi SIMDA Perencanaan web based. }\end{array}$ \\
\hline & & $\begin{array}{l}\text { b. Bimtek kepada seluruh fungsi perencanaan } \\
\text { (Bappeda dan SKPD). }\end{array}$ \\
\hline & & $\begin{array}{l}\text { c. Input data dalam proses perencanaan Tahunan ( } \\
\text { Asistensi BPKP). }\end{array}$ \\
\hline & & $\begin{array}{l}\text { d. Koneksi dengan Pengelolaan Keuangan (SIMDA } \\
\text { Keuangan). }\end{array}$ \\
\hline & & $\begin{array}{l}\text { e. Output nya berupa dokumen perencanaan RKPD, } \\
\text { Renja dan PPAS. }\end{array}$ \\
\hline
\end{tabular}

Sumber data: Materi SIMDA Perencanaan BPKP 
Lewat tahapan Implementasi diatas BAPPEDA Provinsi Utara telah melakukan dan melaksanakan sehingga proses Perencanaan Pembangunan Daerah selaras dengan program dan dapat dianggarkan.

\subsection{Pembahasan}

Penerapan pertama kali yang dilakukan BAPPEDA Sulawesi Utara dalam mengimplementasikan e-planning yaitu:

1. Ketika RPJMD/Renstra telah berjalan, maka RPJMD dan Renstra yang telah disusun di luar aplikasi, di entry ke dalam aplikasi.

2. Untuk menjalankan proses Musrenbang Desa dan Kecamatan, sekurang-kurangnya Renja Awal telah dipilah kegiatan yang akan ditawarkan ke Musrenbang dan ASB sekurangkurangnya telah tersedia untuk kegiatan yang ditawarkan dalam Musrenbang Desa/Kecamatan.

3. Untuk menjalankan proses penyusunan Renja SKPD, telah tersedia ASB/SSH yang memadai.

4. Penerapan dilakukan secara komprehensif, tidak dapat dilakukan parsial untuk beberapa SKPD saja.

\section{KESIMPULAN DAN SARAN}

\subsection{Kesimpulan}

Melalui penelitian ini dapat disimpulkan BAPPEDA Provinsi Sulawesi Utara sudah melaksanakan tahap penginstallan aplikasi, penginputan RPJMD, Analisis Satuan Belanja (ASB) dan Standar Satuan Harga (SSH), dalam aplikasi e-planning. Dengan demikian BAPEEDA Provinsi Sulawesi Utara sudah mengimplementasikan e-planning dan proses selanjutnya BAPPEDA Provinsi Sulwesi Utara dalam proses penyusunan RKPD.

\subsection{Saran}

Diharapkan untuk kedepannya BAPPEDA Provinsi Sulawesi utara dapat menerapkan serta mengoptimalkan penggunaan aplikasi e-planning, sehingga kualitas dokumen perencanaan yang dihasilkan dapat diandalkan yaitu, Perencanaan, Penganggaran, dan Pelaksanaan terhadap program dan kegiatan menjadi selaras antara RPJMD, Renstra, RKPD, Renja, RKA dan DPA.

\section{DAFTAR PUSTAKA}

Undang-Undang Republik Indonesia No. 23 tahun 2014 tentang Pemerintahan daerah Peraturan Menteri Dalam Negeri Republik Indonesia Nomor 86 Tahun 2017 tentang tata cara perencanaan, pengendalian dan evaluasi pembangunan daerah, tata cara evaluasi rancangan peraturan daerah tentang rencana pembangunan jangka panjang daerah dan rencana pembangunan jangka menengah daerah, serta tata cara perubahan rencana pembangunan jangka panjang daerah, rencana pembangunan jangka menengah daerah, dan rencana kerja pemerintah daerah.

Pedoman Pengoperasian SIMDA perencanaan (e-planning) modul parameter lima tahunan dan tahunan oleh BPKP Deputi Pengawasan Bidang Penyelenggaran Keuangan Daerah.

Materi SIMDA Perencanaan Badan Pengawasan Keuangan dan Pembangunan Daerah (BPKP).

Wikipedia, Fungsi Badan Perencanaan dan Pembangunan Daerah [Online] https://id.wikipedia.org/wiki/Badan_Perencanaan_Pembangunan_Daerah, jam 20:10, $\operatorname{tgl} 31$ Oktober 2018. 


Wikipedia, Sejarah $\quad$ Bappeda [Online]
https://id.wikipedia.org/wiki/Badan_Perencanaan_Pembangunan_Daerah, 20:19, 31 Oktober 2018.

Wikipedia, Struktur Organisasi [Online] https://id.wikipedia.org/wiki/Badan_Perencanaan_Pembangunan_Daerah, 20:30, 31 Oktober 2018.s

BAPPEDA SULUT, Tugas Pokok dan Fungsi [Online] http://bappeda.sulutprov.go.id/tugaspokok-dan-fungsi/, 20:45, 31 Oktober 2018.

BAPPEDA SULUT, e-planning [Online] http://bappeda.sulutprov.go.id/e-planning/,. 21:00, 31 Oktober 2018.

Keputusan Mendagri Nomor 185 tahun 1980, tentang Pedoman Organisasi dan Tata Kerja Badan Perencanaan Pembangunan Daerah Tingkat I dan Badan Perencanaan Pembangunan Daerah Tingkat II.

Purnama, Eddy. 2013. "Tata Cara Penyusunan Rencana Pembangunan Daerah Kabupaten/Kota di Aceh”. Kanun Jurnal Ilmu Hukum., No.59, Th. XV(April, 2013), pp. 1-26.

Darlina, Merry., Yannizar., Hodijah, Siti. 2016. “Analisis Perencanaan dan Penganggaran Pada Dinas Pendidikan Provinsi Jambi". Jurnal Perspektif Pembiayaan dan Pembangunan Daerah., Vol. 3 No. 4, April-Juni 2016., ISSN: 2338-4603 (print); 2355-8520 (online).

Ditjen Bina Pembangunan Daerah Kementrian Dalam Negeri,. Penerapan Aplikasi eplanning Dalam Perencanaan Pembangunan Daerah dan SIMDA sebagai alternatif aplikasi penilaian Kinerjra Instansi Pemertintah daerah [Online] http://www.bangda.kemendagri.go.id/berita/baca_kontent/1077/penerapan_aplikasi_e =

planning_dalam_perencanaan_pembangunan_daerah_dan_simda_sebagai_alternatif_a plikasi_penilaian_kinerja_instansi_pemerintah_daerah,. 13:00, 20 November 2018.

Indonesia, Integra. Sistem Informasi Perencanaan Pembangunan E-planning [Online] https://www.integraindonesia.co.id/e-planning/., 14:30, 20 November 2018.

Berita, Formasi., Definisi Perencanaan Pembangunan Daerah [Online] https://formasiberita.blogspot.com/2017/11/defenisi-perencanaan-pembangunandaerah.htmlhttps://formasiberita.blogspot.com/2017/11/defenisi-perencanaanpembangunan-daerah.htmlhttps://formasiberita.blogspot.com/2017/11/defenisiperencanaan-pembangunan-daerah.html,. 15:00, 20 November 2018. 